ECONOMICS

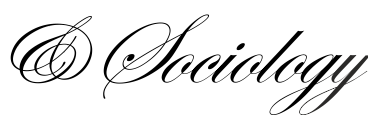

JEL Classification: G34, P37

Stjepcevic, J. (2018). Level (Quality) of Corporate Governance in Adriatic Seaports. Economics and Sociology, 11(1), 325-334. doi:10.14254/2071789X.2018/11-1/21

\title{
LEVEL (QUALITY) OF CORPORATE GOVERNANCE IN ADRIATIC SEAPORTS
}

DOI: $10.14254 / 2071-$

789X.2018/11-1/21

\author{
Received: September, 2017 \\ 1st Revision: December, 2017 \\ Accepted: January, 2018 \\ University of Montenegro, \\ Kotor, Montenegro, \\ E-mail:jstjepcevi@@gmail.com
}

\begin{abstract}
Institutions and institutional structures always determine the development (social and economic), and therefore the level (quality) of microeconomic institutions, including that of corporate governance. The subject of this research is the level (quality) of corporate governance (as a dependent variable in the given model) in relatively undeveloped Adriatic seaports. The aim of this paper is to demonstrate the importance of institutional framework in regulating corporate governance and to verify the hypothesis on a significant dependency of the dependent variable from the selectively chosen independent variables of a dominant institutional character. Field survey methods and multiple linear regression analysis are used in this paper. It is concluded that the offered research has verified the initial hypothesis.
\end{abstract}

Keywords: corporate governance, institutions, seaports,

institutional framework

\section{Introduction}

Non-transparent corporate relations, incomplete privatization results and also secrecy of the larger share of business data on Adriatic seaports Koper (Slovenia), Rijeka (Croatia) and Bar (Montenegro) make it impossible to define, through a comparative analysis, the level and the quality of corporate governance in them. In these seaports, formalism is obviously present when it comes to application of the adopted principles (codes) of corporate governance in practice, and this suggests a relatively low quality of corporate governance as such. All three mentioned above seaports are characterized by similar problems: incomplete definition of the public-private sector relationship and significant involvement of the state into management processes ("managers with high salaries and no responsibilities", as it is described in (Draskovic, 2016).

The paper attempts to prove that the relatively low level of development of corporate governance in these ports is primarily the result of an unfavorable institutional environment, which is structured using five independent variables in the hypothetical model offered by the author.

\section{Literature review}

Different economic theories (ownership, stakeholder, agent relations, governance, institutions, etc.) analyze modern corporations and corporate governance from the aspect of the 
dominant role of institutional factors in their formation, existence and development. R. Apreda (2008) formulated an integrated institutional approach to corporate governance. He identified seven mutually related elements, which form its basis: A constitution, A system of rights and duties, Mechanisms for accountability and transparency, Monitoring and performance measures, Stakeholder rights, Good governance standards, and Independent gatekeepers. Most of them contain institutional aspects.

External institutional environment is a set of rules that regulate complex corporate relations between the legislature, the private sector (shareholders), the financial sector, then various stakeholders, agents that affect the reputation of the company, market entities, and all other stakeholders. It consists of meta-constitution rules, constitution rules, and economic rules, which essentially protect, specify, and regulate property rights (Aoki, 2000; Aguilera and Jackson, 2003).

Corporate governance has not yet been affirmed in many transition economies (Draskovic and Stjepcevic, 2012), because it is an underdeveloped or insufficiently developed institutional environment. In conditions of institutional protection of business and knowledge, the protection of shareholders and investors, which should be provided by corporate management, is not possible. Broader social, institutional, and economic reforms are necessary for its revival and functioning. The basic institutional foundations of corporate governance (state, market, and ownership regulation) in observed transition states (Slovenia, Croatia, and Montenegro) were unstable.

It was logical for ownership transformation (privatization) to lead to the increased motivation mechanism and positive changes in organizational structures of seaports, which would be gradually and functionally adjusted to active participation of corporate governance principles. What happened in practice was not illogical (it has an economic explanation for its own interest), but in terms of realized economic results of seaports, it was dysfunctional and contrary to the principles of corporate governance. Few people were interested in the development of seaports, while personal gain was of primary interest. This was objectively possible to achieve only in terms of institutional vacuum.

Although corporate governance is the institution per se, it seems that its institutional frameworks have not been sufficiently explored in literature (Roe, 2004; Dixit, 2009). The pioneering steps were made by O. Williamson (1993, p. 80). For this topic are significant researches in the field of internal and external corporate governance institutions (Postma and Hermes, 2002; Nee, 2003; Fiss, 2008; Estrin and Prevezer, 2011; Draškovic and Stjepcevic, 2012).

V. Nee (2003, p. 26) shows schematically the multi-level causal model of the institutional framework and institutional environment in new institutional economics. He believes that the institutional environment consists of the formal regulatory rules, which are created, controlled, and applied by the state. Through it they manage property rights, markets, and companies. and impose various restrictions on companies and individuals through market mechanisms and state regulation. That way, the structure of preferences and incentives is formed. Within these various controls and coordinations, there is a corporate governance system that has implicit and explicit relationships with its constituents and participants. Many other authors also consider that corporate governance can be considered an institutional matrix, which defines the role of its subjects ("players"), and the objectives toward which the corporation should guide them, and that is primarily competitiveness.

Due to the inability to conduct a different research and assessment of the level and quality of corporate governance in the observed seaports, we decided to explore the above mentioned topic on the basis of the conducted survey.

We surveyed 50 experts in each of the mentioned ports and their business (partner) environment. The survey was adapted to the model survey, which we performed on the basis 
of multiple regression analysis, in which the level (quality) of corporate governance (Dv) figures as as the dependent variable, whereas five most important parameters (indicators) of corporate governance figure as the independent variable, selectively selected as follows:

- Iv1 - unprotectedness and non-transparency of property rights (see eg. Weingast, 1993; Draskovic et al., 2017),

- Iv2 - instability of the institutional environment (North, 1990; Williamson, 1993) and the deficit of corporate legislation (Demski, 2003; Polterovich, 2012),

- Iv3 - Rent-seeking by ruling nomenclature (Acemoglu et al., 2004; Draskovic, 2017; Draskovic et al., 2016),

- Iv4 - opportunistic behavior and privileged conditions for uncontrolled privatization, instead of legality and competitiveness, which would provide effective owners (Vickers and Yarrow, 1988, 1991; Nellis, 2001; Delibasic, 2016; Popov and Ersh, 2016) i

- Iv5 - unprotected shareholders (Zingales, 1995, 1997).

\section{Research framework: modeling independent and dependent variable}

For the purposes of this research, a survey was prepared in accordance with the previously presented theoretical framework. In total, 150 highly educated respondents, experts, who are business related to the ports of Bar (50 respondents), Rijeka (50 respondents) and Koper (50 respondents) were surveyed. Respondents answered six questions related to the subjective degree (level) of experience in which the independent variables were given. The schematic view of the research framework is given in Figure 1.

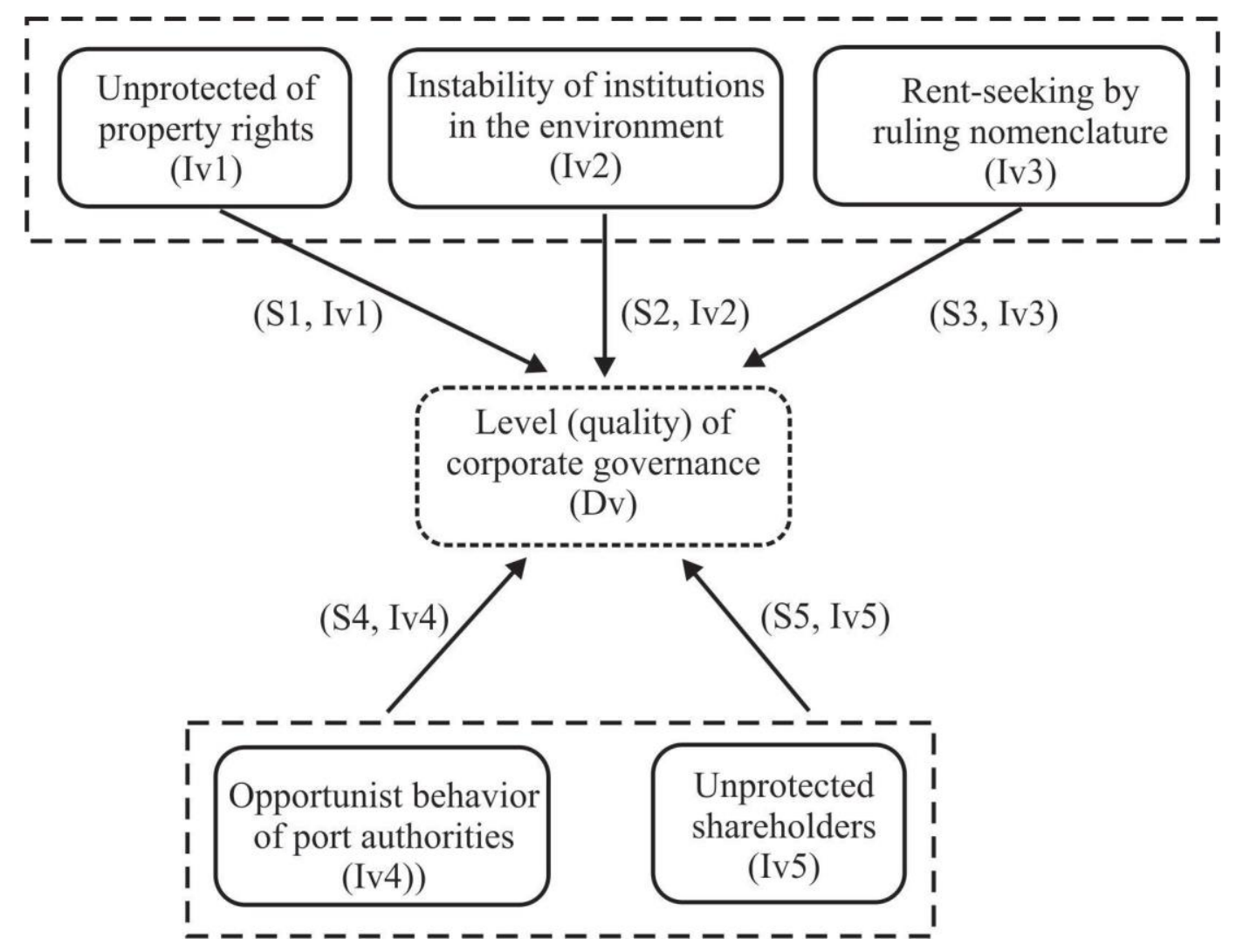

Figure 1. Research framework: modeling of independent and dependent variables

The constructs used in this study were measured with the Likert scale from 1 to 5 . In order to express a subjective assessment of the impact of independent variable on the dependent 
variable the respondents used the following linguistic qualifiers: very strong (5), strong (4), medium (3), weak 2) and very weak (1) impact. Later, the linguistic qualifiers were encoded in the Likert scale, with the corresponding number values being previously indicated in parentheses next to each of the linguistic qualifiers. Based on this, we have made the appropriate survey.

\subsection{Multiple linear regression model}

By using this model, the goal is to determine the functional dependence between the dependent variable (Dv) and the independent variables (Iv1, Iv2, Iv3, Iv4 and Iv5). It is necessary to determine the mean expected value of the dependent variable $(\overline{\mathrm{Dv}})$, on the basis of the individual estimates of the respondents. Since the respondents have evaluated the dependent and the independent variables in accordance with their subjective judgments and years of experience, our task was to determine the coefficients: I, S1, S2, S3, S4 and S5, by using the expression (1):

$$
\overline{\mathrm{Dv}}=\mathrm{I}+\mathrm{S} 1 * \mathrm{Dv} 1+\mathrm{S} 2 * \mathrm{Dv} 2+\mathrm{S} 3 * \mathrm{Dv} 3+\mathrm{S} 4 * \mathrm{Dv} 4+\mathrm{S} 5 * \mathrm{Dv} 5
$$

Where,

$\overline{\mathrm{Dv}}$ - is the mean expected value of the dependent variable;

I - is the intercept, determined on the basis of an appropriate sample;

S1, S2, S3, S4, and S5 - are coefficients of independent variables Iv1, Iv2, Iv3, Iv4, and Iv5, which represent the slopes of the correspondent lines to the abscissa. On the basis of these values, for any new value of each independent variable from a predefined interval, we can estimate the value of the dependent variable. Accordingly, it should be said that $\overline{\mathrm{Dv}}$ is an average estimated value due to Iv1, Iv2, Iv3, Iv4 and Iv5. To determine $\overline{\mathrm{Dv}}$ it is used the last square method (Bertskas and Tsitsiklis, 2008). Our goal was to determine the coefficients: I, S1, S2, S3, S4, and $\mathrm{S} 5$, so as to minimize the sum of squared errors (SSE), which is represented by (2):

$$
\begin{aligned}
& \mathrm{SSE}=\sum_{\mathrm{k}=1}^{\mathrm{n}}\left(\mathrm{Dv}_{\mathrm{k}}-\overline{\mathrm{Dv}}_{\mathrm{k}}\right)^{2}= \\
& =\sum_{\mathrm{k}=1}^{\mathrm{n}}\left(\mathrm{Dv} \mathrm{v}_{\mathrm{k}}-(\mathrm{I}+\mathrm{S} 1 * \mathrm{Iv} 1+\mathrm{S} 2 * \operatorname{Iv} 2+\mathrm{S} 3 * \operatorname{Iv} 3+\mathrm{S} 4 * \operatorname{Iv} 4+\mathrm{S} 5 * \operatorname{Iv} 5)\right)^{2}
\end{aligned}
$$

Where,

$D v_{k}-$ is actual value of the dependent variable, given by the $\mathrm{k}$ respondents $(\mathrm{k}=\overline{1, \mathrm{n}})$;

$\overline{\mathrm{Dv}}_{\mathrm{k}}$ - is the estimated value of the dependent variable on the basis of the model, in the case of $\mathrm{k}$ respondents $(\mathrm{k}=\overline{1, \mathrm{n}})$;

$\mathrm{n}$ - is the total number of respondents (50 experts from Montenegro, i.e., from Port of Bar; 50 experts from Croatia, i.e., from Port of Rijeka; and 50 experts from Slovenia, i.e., from Port of Koper), $\mathrm{k}=\overline{1, \mathrm{n}}(\mathrm{n}=150)$.

Using the least-squares method, here is actually determined a straight line, which minimizes the sum of vertical differences for each pair of points (Balakrishnan et al., 2007). In 
other words, a straight line that best fits the given set of points, by deriving the optimal value of intercept (I), as well as the coefficients (S1, S2, S3, S4, and S5) has been determined. Actually, the optimal mean value of the dependent variable $\overline{\mathrm{Dv}}$ has been calculated, for the subjectively estimated values of the independent variables (Iv1, Iv2, Iv3, Iv4 and Iv5), and dependent variable (Dv), for $\forall \mathrm{k}, \mathrm{k}=\overline{1, \mathrm{n}}$.

\section{Results of the regression analysis}

The realization of multiple linear regression model has been made by computer programs, i.e, by a special MS Excel VBA tool used as a Module Solver and SPSS (Sheridan and Coakes, 2013; Pallant, 2011). Calculus are realized by an Inter(R) Core ${ }^{\mathrm{TM}}$ i5 processor on $2.4 \mathrm{GHz}$ (4GB RAM). Besides linear regression key parameters: I, S1, S2, S3, S4, and S5, following statistical parameters are calculated: MAD - mean absolute deviation, MSE - mean square error, MAPE - mean absolute percent error, SE - standard error of the regression estimate, $r$ - correlation coefficient, and $r^{2}$ - coefficeint of determinantion.

Table 1. Key statistics for the multiple linear regression model

\begin{tabular}{cccc}
\hline Statistics & Port of Bar & Port of Rijeka & Port of Koper \\
\hline I & 0.560 & 1.472 & 2.519 \\
\hline S1 & 0.111 & 0.108 & 0.416 \\
\hline S2 & 0.321 & 0.221 & -0.321 \\
\hline S3 & 0.250 & 0.143 & 0.152 \\
\hline S4 & -0.132 & -0.084 & 0.244 \\
\hline S5 & -0.014 & 0.072 & -0.346 \\
\hline MAD & 0.399 & 0.565 & 0.369 \\
\hline MSE & 0.281 & 0.446 & 0.233 \\
\hline MAPE & $22.92 \%$ & $22.01 \%$ & $13,84 \%$ \\
\hline SE & \pm 0.565 & \pm 0.712 & \pm 0.514 \\
\hline r & 0.387 & 0.322 & 0.543 \\
\hline r & 0.150 & 0.104 & 0.294 \\
\hline
\end{tabular}

MAD - mean absolute deviation demonstrates to what extent the obtained value of the dependent variable, obtained by multiple linear regression analysis, corresponds to the estimates of the respondents. In fact, it shows the extent to which the model reflects the estimates of the respondents. The concrete values of mean absolute deviation of the samples for the ports of Bar, Rijeka and Kopar are respectively: 0.399; 0565; 0369. These values point to a solid correlation of the model and the respondents' evaluations.

MSE - mean square error in estimation takes the values of: $0.281 ; 0.446$ and 0.233 , respectively, in the cases of analyzed samples pertaining to the ports, which are investigated. These numerical values are in favor of a satisfactory compliance of the model and the data collected through surveys.

MAPE - mean absolute percent error is the error in the estimation of the dependent variable by the respondents and by the model. In the case of our research it takes values of: $23 \%, 22 \%$ and $13 \%$, respectively. These values also point to the appropriate level of correspondence between the model and the assessment of the respondents.

$\mathrm{SE}$ - standard error of regression, or standard deviation of regression, is suitable for formation of so-called ,interval of confidence around the regression line“. It shows how the 
dependent variable value, obtained by the model, can vary. In our research, the standard deviation has the values: $\pm 0.565 ; \pm 0.712$ and \pm 0.514 .7 , respectively.

$\mathrm{r}$ - correlation coefficient determines the strength of linear dependence. If it is greater than 0.6 , linear dependence is considered to be very strong. In the specific cases being analyzed, $r$ is: $0.387 ; 0.322$ and 0.543 , respectively, which does not indicate strong linear dependence and therefore there is a need to introduce additional variables in the model, or to use some other form(s) of dependence among variables in the further research work.

$\mathrm{r}^{2}$ - coefficient of determination is a value from 0 to 1 , which can be expressed in percentage that shows in which percentage dependent variable depends on independent variables. In the analyzed cases, these percentages are quite small (15\%, $10 \%$ and 29\% respectively), so in the further research experiments, the model should be modified, some variables might be excluded and some other included, or, another model of functional dependency between variables (square, logarithmic, etc.) might be used. However, for the purposes of this research, we find this model satisfactory because we get an overview of the level and quality of corporate governance in the three regional ports. These ports have certain economic, administrative and organizational specificities in their functioning, whereby the results obtained by the model correspond essentially to the real situation.

According to the data given in Table 1, the lines that represent the functional dependencies between the dependent (Dv) and independent variable (Iv1-5) are given below.

- Case 1: Port of Bar:

$$
\overline{\mathrm{Dv}_{\mathrm{BAR}}}=0.111 \cdot \operatorname{Iv} 1+0.321 \cdot \operatorname{Iv} 2+0.250 \cdot \operatorname{Iv} 3-0.132 \cdot \operatorname{Iv} 4-0.014 \cdot \operatorname{Iv} 5+0.560
$$

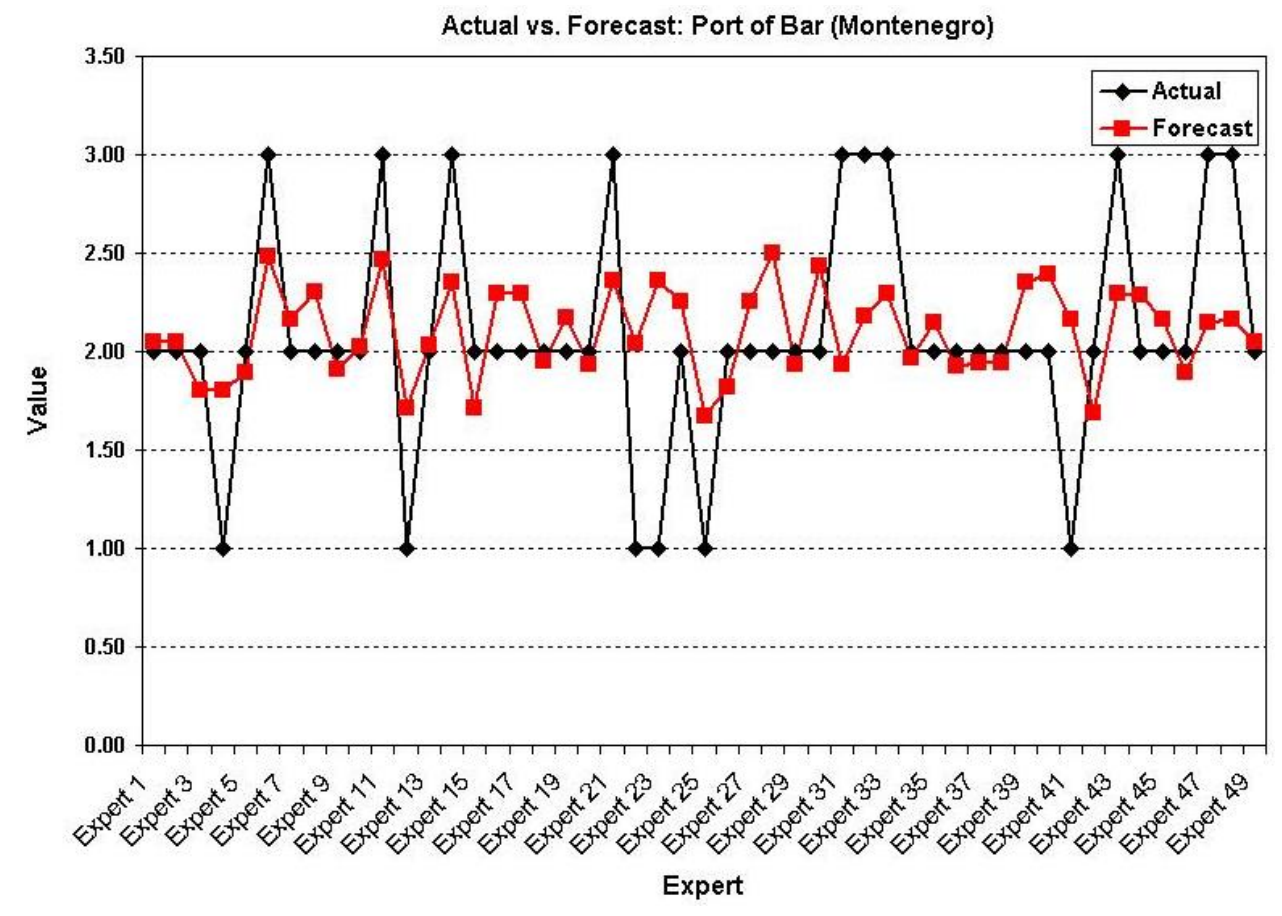

Figure 2. The relationship between dependant variable values estimeded by the experts and by the model: Case of the Port of Bar

- Case 2: Port of Rijeka:

$$
\overline{\mathrm{Dv}_{\mathrm{RIJEKA}}}=0.108 \cdot \mathrm{Iv} 1+0.221 \cdot \mathrm{Iv} 2+0.143 \cdot \mathrm{Iv} 3-0.084 \cdot \mathrm{Iv} 4+0.072 \cdot \mathrm{Iv} 5+1.472
$$




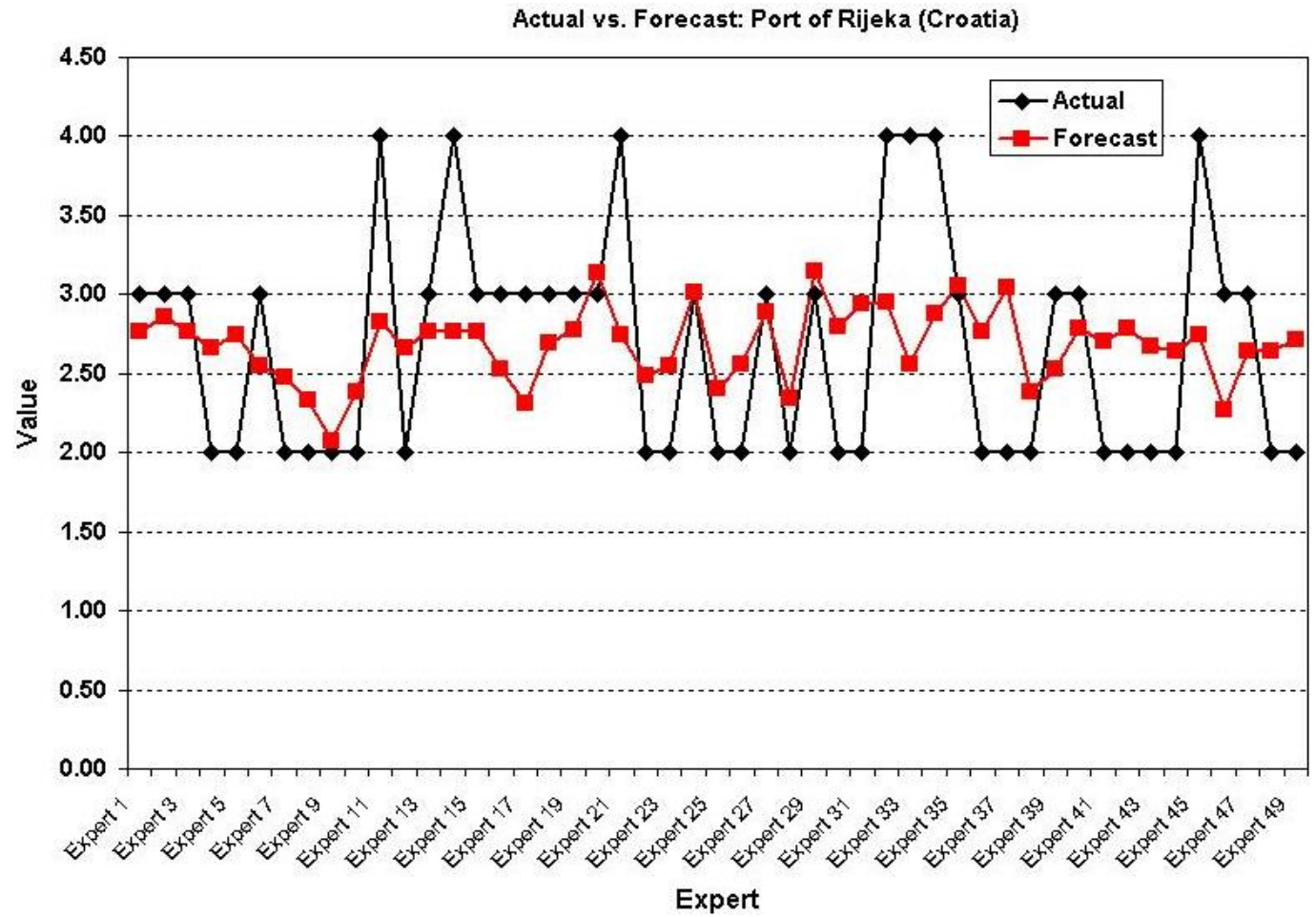

Figure 3. The relationship between dependant variable values estimeded by the experts and by the model: Case of the Port of Rijeka

- Case 3: Port of Koper:

$$
\overline{\mathrm{Dv}_{\mathrm{KOPAR}}}=0.416 \cdot \mathrm{Iv} 1-0.321 \cdot \mathrm{Iv} 2+0.152 \cdot \mathrm{Iv} 3+0.244 \cdot \mathrm{Iv} 4-0.346 \cdot \mathrm{Iv} 5+2.519
$$

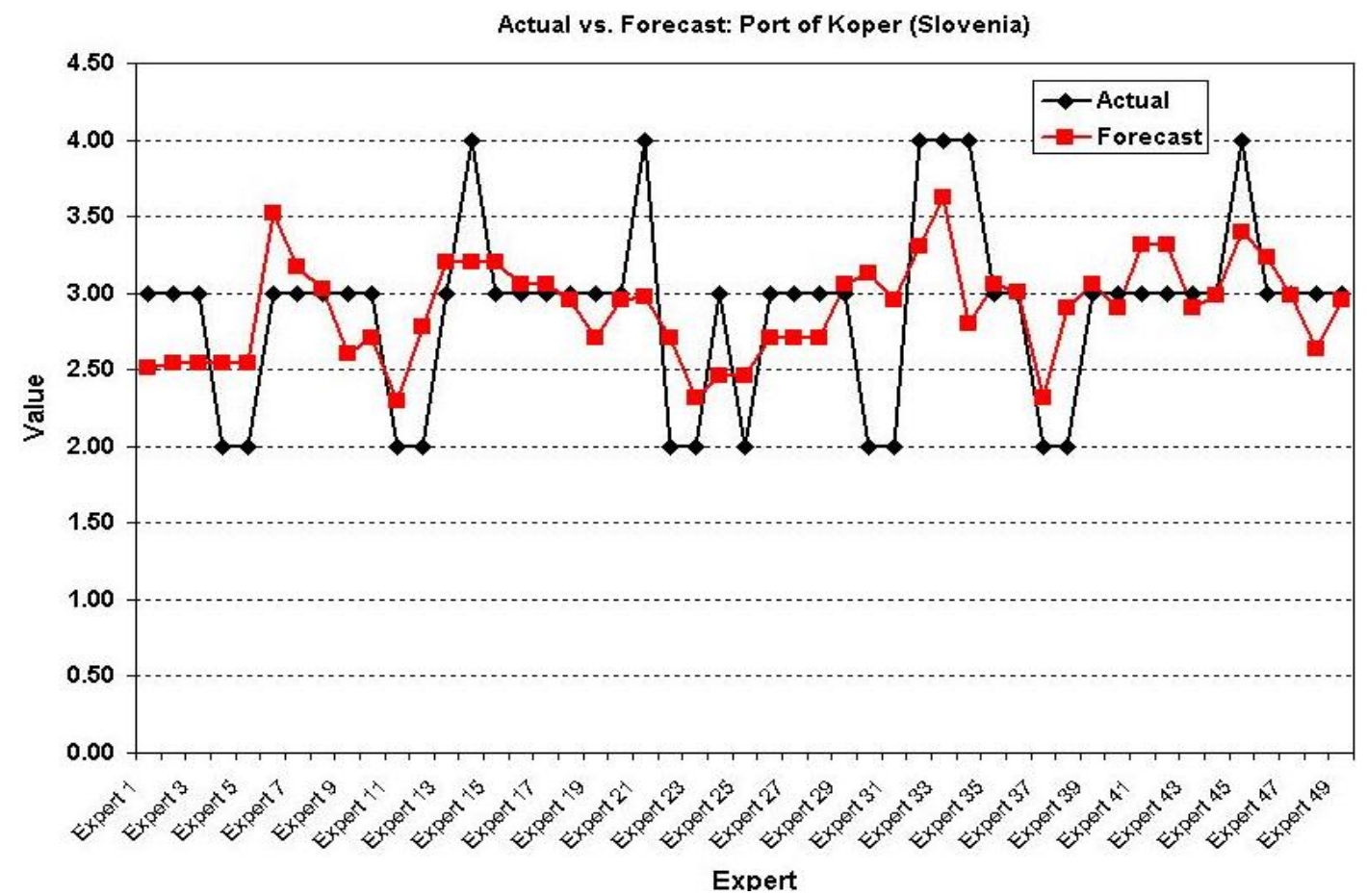

Figure 4. The relationship between dependant variable values estimeded by the experts and by the model: Case of the Port of Koper 
Some additional numerical experiments have been made in SPSS (version 17.0). The mean values of dependent and independent variables, estimated (preliminarily) by the respondents (i.e., by the experts) are shown in Figure 5 (below) and categorized into clusters pertaining to each of the analyzed ports in the region. These values correspond quite well to the results obtained by the model.

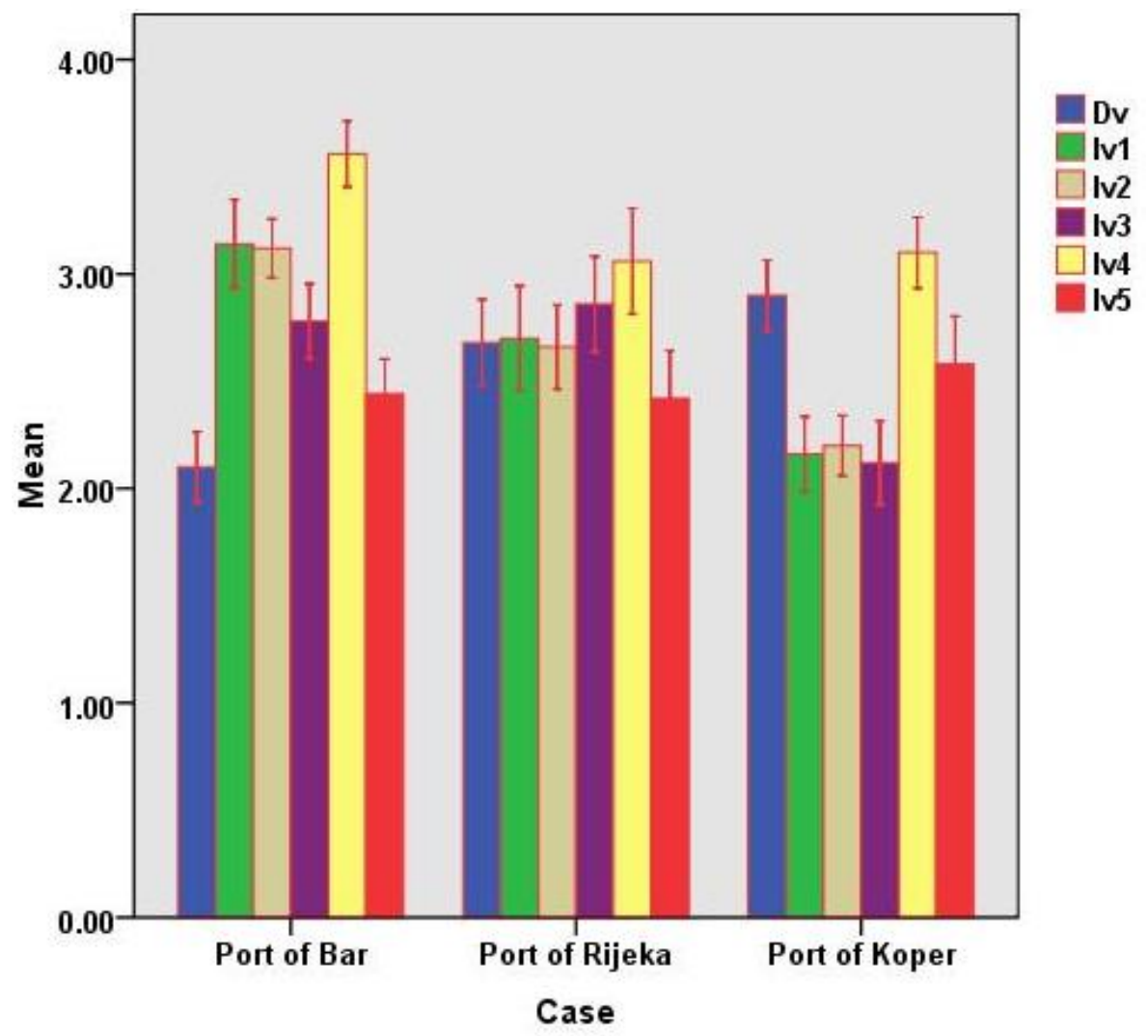

Error bars: $95 \% \mathrm{Cl}$

Figure 5. Mean values of the preliminary experts' estimations of the variables in the model for three analyzed cases

\subsection{Discusion}

According to the conducted research, the highest level and quality of corporate governance is present in the Port of Koper, then in the Port of Rijeka and the lowest in the Port of Bar. In all three analyzed cases, the opportunistic behavior of port authorities and privileged conditions for uncontrolled privatization has the greatest negative impact on the level and quality of corporate governance. In the case of the Montenegrin Port of Bar, at the second place there is - the lack of protection of private property, in the case of the Croatian Port of Rijekathe possibility of withdrawal of an annuity by the nomenclature of power, and in the case of the Slovenian port (Kopar) - the instability of the institutional environment. It has been previously established that the proposed model with relatively small errors over the entire sample $(23 \%$, $22 \%$ and $13 \%$ ) describes the expert's estimates.

The following conclusion is drawn: in the mentioned field research, based on analyzes carried out among experts in the field of port operations from Montenegro (Port of Bar), Croatia (Port of Rijeka) and Slovenia (Luka Koper), a theoretical and methodological framework for quantitative modeling level and quality of corporate governance (dependent variable) is proposed, caused by the above mentioned independent variables. 
Multiple linear functional dependencies between dependent and independent variables are established for each of the analyzed ports. It was found that the level and quality of corporate management in the case of the Port of Bar were assessed as weak (2), and in the case of the Port of Rijeka and Koper as medium (3), with smaller or higher variations. Also, the degree of influence that the independent variables have on dependent variable is determined, in the case of each of the analyzed samples from the three observed ports. Additionally, the level of influence of independent variables on the dependent variable at the level of the overall sample was established, with the general dominance of the opportunistic behavior of port authorities in the sense of a markedly negative impact on the level and quality of corporate governance.

\section{Conclusions}

Since all independent variables have an institutional character, it can be safely concluded that most of the privatization and corporate governance problems in the considered Adriatic seaports must be sought in the existence of an underdeveloped and dysfunctional institutional structure.

Hypothetical research showed the expected relatively low level (quality) of corporate governance in the observed Adriatic seaports of Koper, Rijeka and Bar. The given order follows the obtained results, with the Port of Bar significantly lagging behind in the application and development of corporate governance, in all selected parameters.

Further research should be carried out with the possible inclusion of additional independent variables, or the establishment of different, more complex aspects of the functional interdependence of the variables. In addition, in-depth interviews with respondents should be carried out instead of the survey, and in this way determine the reasons for their commitment to a particular linguistic, that is, quantitative value of the degree of influence of certain socioeconomic disorders on the level and quality of corporate governance.

\section{References}

Acemoglu, D., Johnson, S., Robinson, J. (2004). Institutions as the Fundamental Cause of Long-Run Growth, In: Aghion, Ph., Durlauf, St. (eds.). Handbook of Economic Growth, North Holland.

Aguilera, R. V., Jackson, G. (2003). The Cross-national Diversity of Corporate Governance Dimensions and Determinants. Academy of Management Review, 28(3), 447-465.

Aoki, M. (2000). Information, Corporate Governance and Institutional Diversity: Competitiveness in Japan, the USA and Transitional Economies. Oxford University Press, Oxford.

Apreda, R. (2008). The Semantics of Governance, In: Clarke, T. and dela Rama, M. (eds.), The Fundamentals of Corporate Governance, Volume 1: Ownership and Control, SAGE Publications, London, pp. 10-23.

Balakrishnan, N., Render, B., Stair, R. M. (2007). Managerial Decision Modeling with Spreadsheets. Prentice-Hall Inc., New Jersey.

Bertskas, D. P., Tsitsiklis, J. N. (2008). Introduction to probability. Athena Scientific, USA.

Coakes, S. J. (2013). SPSS 20.0 for Windows - Analysis without Anguish. Willey Publishing, Inc.

Delibasic, M. (2016). Hypothetical Matrix for Institutional Modeling of the Basis for Economic Development in the Countries of Southeast Europe. Montenegrin Journal of Economics, 12(2), 147-159. DOI: 10.14254/1800-5845.2016/12-1/9

Demski, J. S. (2003). Corporate conflicts if interest. Journal of Economic Perspectives, 17(2), 51-72. 
Dixit, A (2009). Governance Institutions and Economic Activity. American Economic Review, 99(1), 5-24.

Draskovic, M. (2016). Roots and Paradoxes of the Neoliberal Apologetics. Economics and Sociology, 9(1), 209-219, DOI: 10.14254/2071-789X.2015/9-1/1.

Draskovic, M. (2017). Possibilities and Limitations of Neoinstitutional Economic Theory in Explaining the Transition Crisis - the Case of Montenegro. Transformations in Business \& Economics, 16(3/4), 164-174 .

Draškovic, M., Stjepcevic, J. (2012). Institutional Framework of Corporate Governance With Reference to the Former Yugoslav Transition Economies. Montenegrin Journal of Economics, 8(4), 27-41.

Draskovic, M., Bauk, S., Delibasic, M. (2016). Testing the Level and Factors of Institutional Rationality in Montenegro, Serbia and Bosnia and Herzegovina. Economics and Sociology, 9(2), 22-40.

Draskovic, V., Popov, E., Peleckis, K. K. (2017). Modelling of Institutional Changes in Transition Countries - the Gap Between the Theory and Practice. Montenegrin Journal of Economics, 13(1), 125-140. DOI: 10.14254/1800-5845/2017.13-1.9

Estrin, S., Prevezer, M. (2011). The Role of Informal Institutions in Corporate Governance: Brazil, Russia, India and China Compared. Asia Pacific Journal of Management, 28(1), 41-67.

Fiss, P. C. (2008). Institutions and Corporate Governance, In: The Sage Handbook of Organizational Institutionalism. Sage Publications, Los Angeles, pp. 389-410.

Nee, V. (2003). New Institutionalism, Economic and Sociological. Princeton University Press, Princeton.

Nellis, J. (2001). The World Bank, Privatization and Enterprize Reform in Transition Economies: A Retrospective Analysis. Working Paper, Center for Global Development. Washington, D. C.

North, D. C. (1990). Institutions, institutional change and economic performance. Cambridge University Press, Cambridge, MA.

Pallant, J. F. (2011). SPSS Survival Manual: A Step by Step Guide to Data Analysis Using SPSS. Allen \& Unwin, Australia.

Polterovich, V. (2012). Reform Design: How to Search for Interim Institutions. Montenegrin Journal of Economics, 8(2), 25-44.

Popov, E. V., Ersh, E. V. (2016). Institutions for Decreasing of Employee Opportunism. Montenegrin Journal of Economics, 12(2), 131-146. DOI: 10.14254/1800-5845.2016/12-1/2.

Postma, T., Hermes, N. (2002). Institutions, Corporate Governance and Corporate Governance Institutions: The Case of Estonia. Getting Ready for a Larger EU: Governance, Institution Design and the Transformation of Business Systems, pp. 20-21, Groningen, http://www. rug.nl/staff/ c.l.m.hermes/corporate_governance_Estonia.pdf, accessed 19.01.2018.

Roe, M. (2004). The Institutions of Corporate Governance. Discussion Paper, No. 488-08, 1-24.

Vickers, J., Yarrow G. (1991). Economic perspectives on privatization. Journal of Economic Perspectives, 5(2), 111-132.

Weingast, B. (1993). Constitutions as Governance Structures: the Political Foundations of Secure Markets. Journal of Institutional and Theoretical Economics, 149, 286-311.

Williamson, O. E. (1993). Transaction Cost Economics and Organization Theory. Industrial and Corporate Change, 2(2), 107-156.

World Economic Forum (2017). WEF's Global Competitiveness Index, Geneva.

Zingales, L. (1995). Insider Ownership and the Decision to Go Public. Review of Economic Studies, 62, 425-448.

Zingales, L. (1997). Corporate Governance. NBER Working Paper, 6309, Cambridge, Mass. 